\title{
Familial pneumothoraces - Birt-Hogg-Dubé syndrome. Differentiation with other cystic lung diseases
}

\author{
Lucyna Opoka ${ }^{1 A, B, D, E, F}$, Jacek Wakulinski ${ }^{1 A, B, D, E, F}$, Jolanta Winek ${ }^{2 A, B, D, E, F}$, Iwona Bestry ${ }^{1 A, D, E, F}$, \\ Katarzyna Błasinska ${ }^{1 A, B, D, E, F}$, Elżbieta Radzikowska ${ }^{3 A, B, D, E, F}$ \\ 'Department of Radiology, National Tuberculosis and Lung Diseases Research Institute, Warsaw, Poland \\ ${ }^{2}$ Outpatient Department, National Tuberculosis and Lung Diseases Research Institute, Warsaw, Poland \\ ${ }_{3}^{3}{ }^{\text {rd }}$ Department of Lung Diseases, National Tuberculosis and Lung Diseases Research Institute, Warsaw, Poland
}

\section{Abstract}

Birt-Hogg-Dubé syndrome (BHDS) is a rare, genetic, autosomal dominant disease caused by mutation in a folliculin gene. This syndrome is characterised by three main symptoms: benign lesions originating from hair follicles, variously shaped cysts in the lungs, and various types of benign and malignant kidney neoplasms. In our article we are going to present cases of two sisters with BHDS. In the case of the first sister skin lesions were accompanied by lung abnormalities. The second sister, however, presented with recurrent pneumothoraces associated with variously shaped lung cysts located mainly below the tracheal carina. In both instance diagnosis was confirmed by genetic test.

Key words: Birt-Hogg-Dubé syndrome, cystic lung diseases, recurrent pneumothoraces, pneumothorax.

\section{Introduction}

Birt-Hogg-Dubé syndrome (BHDS) is a disease caused by autosomal dominant mutation in a folliculin gene (FLCN). The disease manifests by skin lesions (fibrofolliculomas, trichodiscomas, perifollicular fibromas, and acrochordons), lung cysts inducing recurrent pneumothoraces, and kidney neoplasms. BHDS was first described in 1977, and later Chung et al. associated the syndrome with lung cysts [1].

FLCN gene is located on a short arm of the chromosome 17 locus p12-q11.2; it belongs to the family of tumour suppressor genes [2]. The folliculin defect results in the malfunctioning of cell adhesion mechanisms as well as intercellular junctions [3]. In case of developing pulmonary abnormalities, there are suggestions that the "stretching mechanism", which is most prominent in supradiaphragmatic regions, plays an important role. It results in the development of lung cysts located mostly in lower and middle lung zones. In tissue samples acquired from patients with BHDS small nonspecific air spaces are present; they represent cysts that are lined with alveolar epithelium. In 30\% of patients, lung cysts may be the only BHDS manifestation.

\section{Case 1}

A 52-year-old woman presented to the outpatient pulmonology department with results of computed tomography (CT) examinations showing lung cysts located below the tracheal carina. The patient's history was negative for smoking or exposure to any kind of pneumotoxic substance. The patient reported cough with sputum production lasting for a few years. Numerous, soft, whitish-yellow lesions were found on patient's face during physical examination (Figure 1). They represented fibrofolliculomas, which, according to the patient, started to present when she was about 30 years old. Subsequent CT examination

Correspondence address:

Jacek Wakulinski, Department of Radiology, National Tuberculosis and Lung Diseases Research Institute, 26 Płocka St., 01-138 Warsaw, Poland,

e-mail: j.wakulinski@igichp.edu.pl

Authors' contribution:

A Study design · B Data collection · C Statistical analysis · D Data interpretation - E Manuscript preparation · F Literature search · G Funds collection 
revealed multiple, thin walled, differently shaped cysts in both lungs, located predominantly in the lower lung zones (Figure 2). The largest cyst had dimensions of $11 \times 10 \times$ $3.1 \mathrm{~cm}$ (Figures 2B, 3). Abdominal ultrasound examination was normal. Ventilation parameters and diffusing capacity of carbon monoxide were within normal limits. In blood tests none of the inflammatory or cancer markers was elevated. During history gathering, the patient stated that her sister had similar lung cysts and that she had positive history of numerous recurrent pneumothoraces. Because of suspicion of BHDS, a gene test for FLCN was performed. The results were positive for c.1285delC mutation in one of the FLCN alleles, which confirmed the diagnosis of Birt-Hogg-Dubé syndrome.

\section{Case 2}

A 44-year-old woman, a sister of the aforementioned patient, whose history was also negative for smoking and exposure to other pneumotoxic substances, was hospitalised a few times because of recurrent pneumothoraces. Chest $\mathrm{CT}$ revealed numerous thin-walled lung cysts located mostly in lower lung zones (Figure 4A). The largest lung cyst had dimensions of $4.2 \times 2.4 \times 2.1 \mathrm{~cm}$ (Figures $4 \mathrm{~B}, 5$ ). The first pneumothorax occurred when the patient was 34 years old. After reappearance of the pneumothorax three years later, wedge resection of the right lung containing emphysematous bulle was performed (Figure 6). Simultaneously, mechanical abrasion of the pleural cavity was performed. A third pneumothorax occurred seven years later, during infection with persistent cough; it resolved spontaneously. During winters the patient reported dry cough and mild exertional dyspnoea. The patient had no skin lesions. Ventilation parameters and the diffusion capacity of carbon monoxide was within normal limits. Abdominal ultrasound examination was normal.

In histopathological examinations of tissue samples acquired during wedge resection of emphysematous bullae, focal fibrosis and pleural hyperperfusion was noted.

Family history: The parents of the sisters are deceased, and presumably did not have any kind of skin, lung, or kidney lesions; however, we do not have access to their medical records. It should be suspected that one of the parents had congenital genetical mutation, which in turn passed to one of the children.

The presented patients also have a third sister whose high-resolution computer tomography (HRCT) was normal.

A 15-year-old daughter of the second patient has Raynaud syndrome but lacks any other symptoms; we are planning to perform gene test for mutations in FLCN gene after she reaches adulthood.

\section{Discussion}

Birt-Hogg-Dubé syndrome is a rare and hard to diagnose disease. In the whole world there are about 600 families

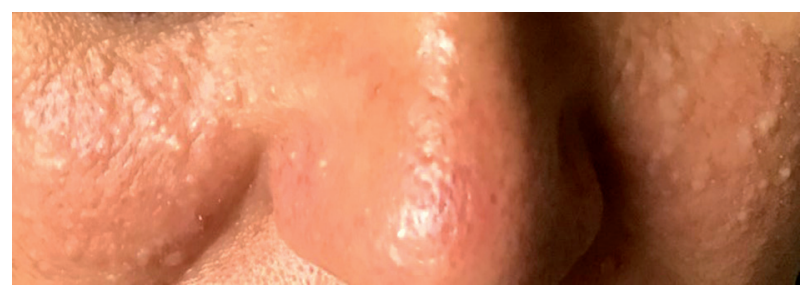

Figure 1. Fibrofolliculomas, dome-shaped, yellowish papules on the cheeks and nose
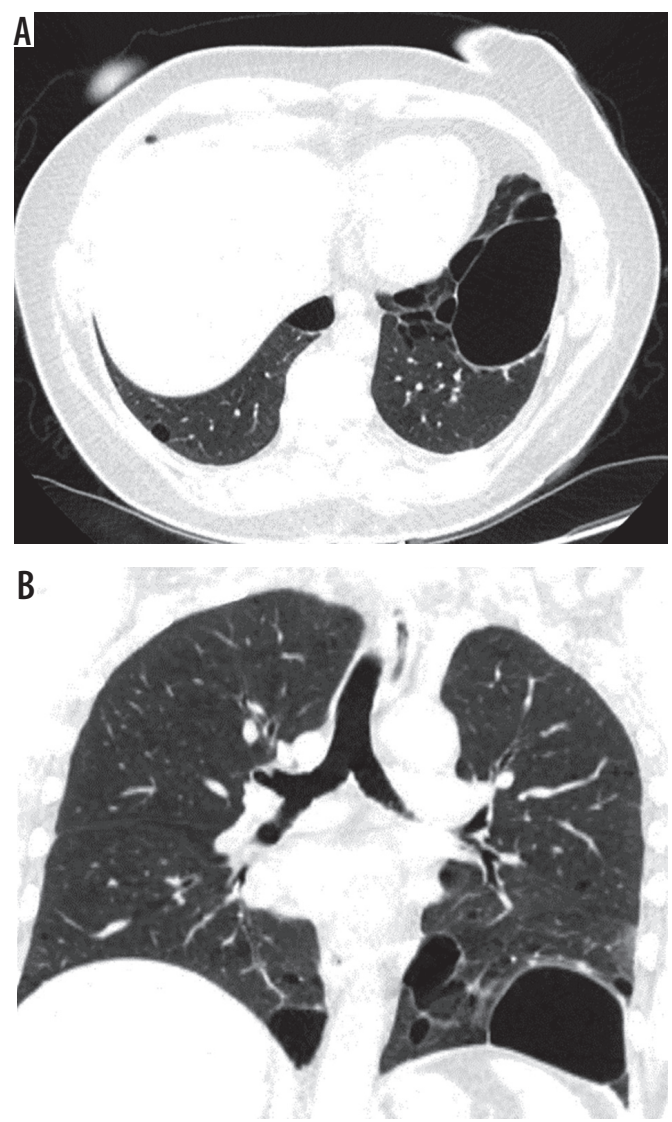

Figure 2. Baseline chest computed tomography, lung window: A) axial plane, B) coronal reconstruction. It shows multiple well-circumscribed, thin-walled, and variable sized lung cysts with round, oval, and irregular shapes with predominantly basal distribution. The largest cyst is located in the left lower lobe

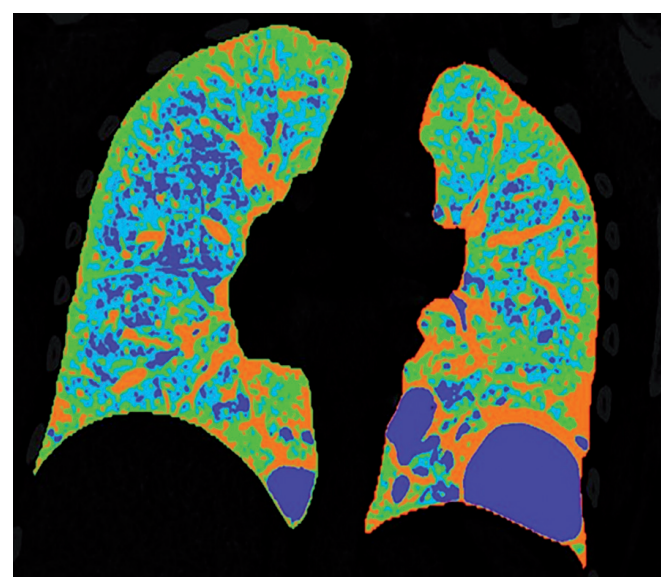

Figure 3. Reconstruction in 3D Pulmo software depicts areas of less than $-950 \mathrm{HU}$ in colour blue 

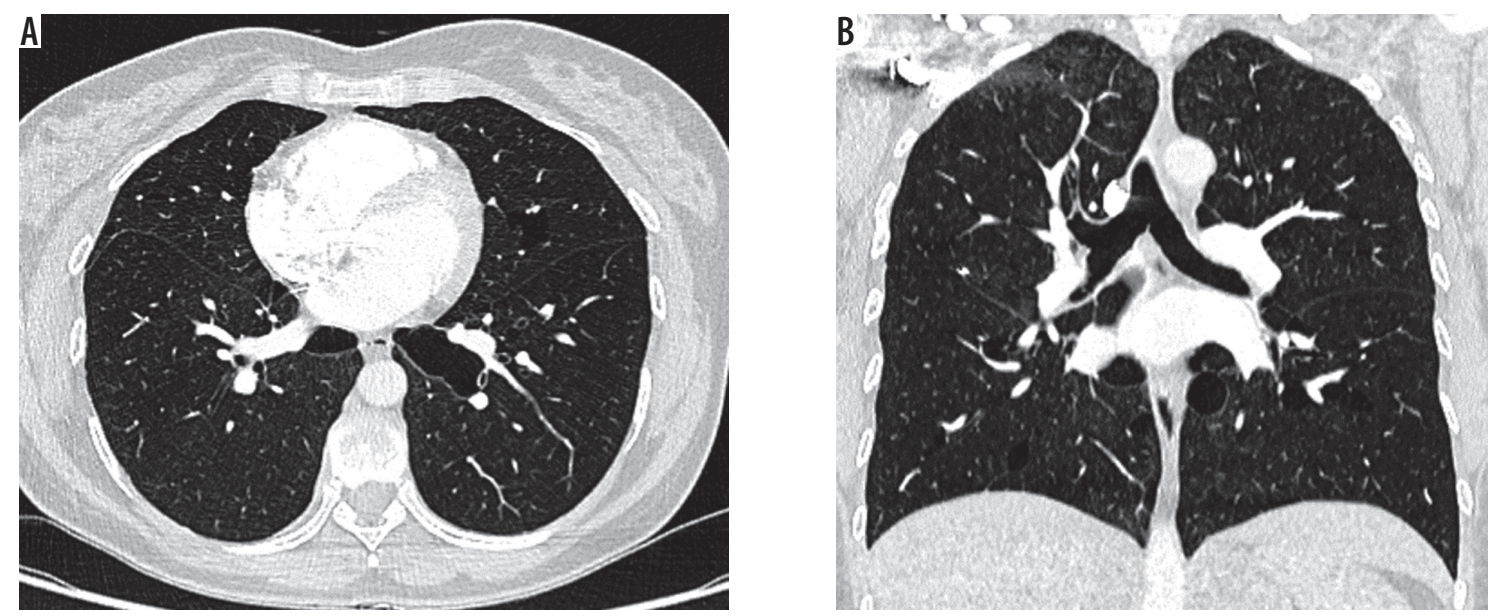

Figure 4. Baseline chest computed tomography, lung window: A) axial and B) coronal plane. (omputed tomography scan shows characteristic distribution of lung cysts predominantly in medial aspect of middle and lower lung zones

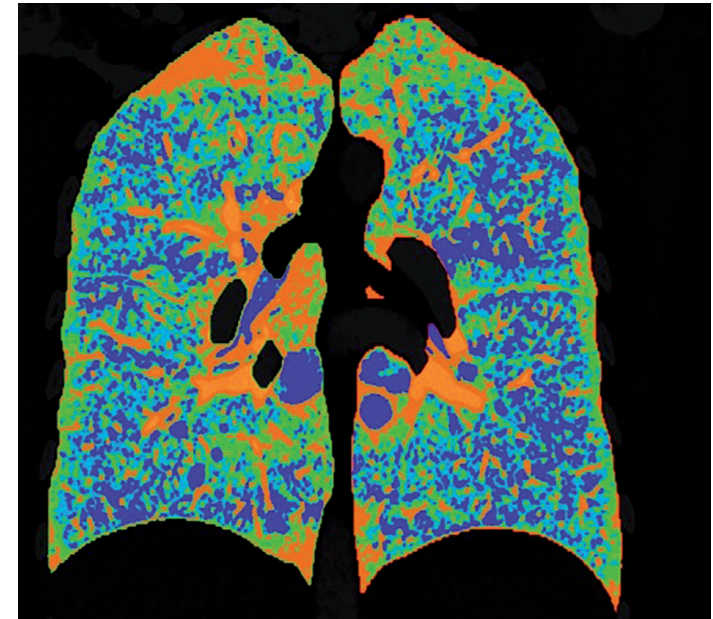

Figure 5. Reconstruction in 3D Pulmo software depicts areas of less than $-950 \mathrm{HU}$ in colour blue

with BHDS. In Poland it was diagnosed and published for the first time in 2016 [4]. Lung cysts start to occur when patients are 30-40 years old [5]. There is no correlation with patients' sex or history of smoking. Lung cysts are found in $77-89 \%$ of patients, and pneumothoraxes develop in $33-38 \%$ [6].

Chest radiographs typically do not show any abnormalities. Sometimes poorly visible lucencies representing lung cysts or pneumothorax can be seen. CT examinations show cysts of variable shapes (round, oval, or lenticular), with well-defined walls, located mostly in middle and lower lung zones. Tobino et al. analysed computed topographies of patients with BHDS and found that most cysts were located in basal medial regions (58\%); less frequently they were seen in basal peripheral regions (27\%). The number of cysts varies from tens to hundreds, their size also varies greatly, but most have a diameter smaller than $1 \mathrm{~cm}$, and approximately $40 \%$ adhere to pleura [7].

The most common clinical manifestation of BHDS are recurrent pneumothoraces.

Zbar et al. reported that the frequency of pneumothorax occurrence increases with the patient's age [8]. The mean age of patients at the time of first pneumothorax occurrence was 38 years, and $75 \%$ of pneumothoraces are recurrent. There is a theory that the size and volume of
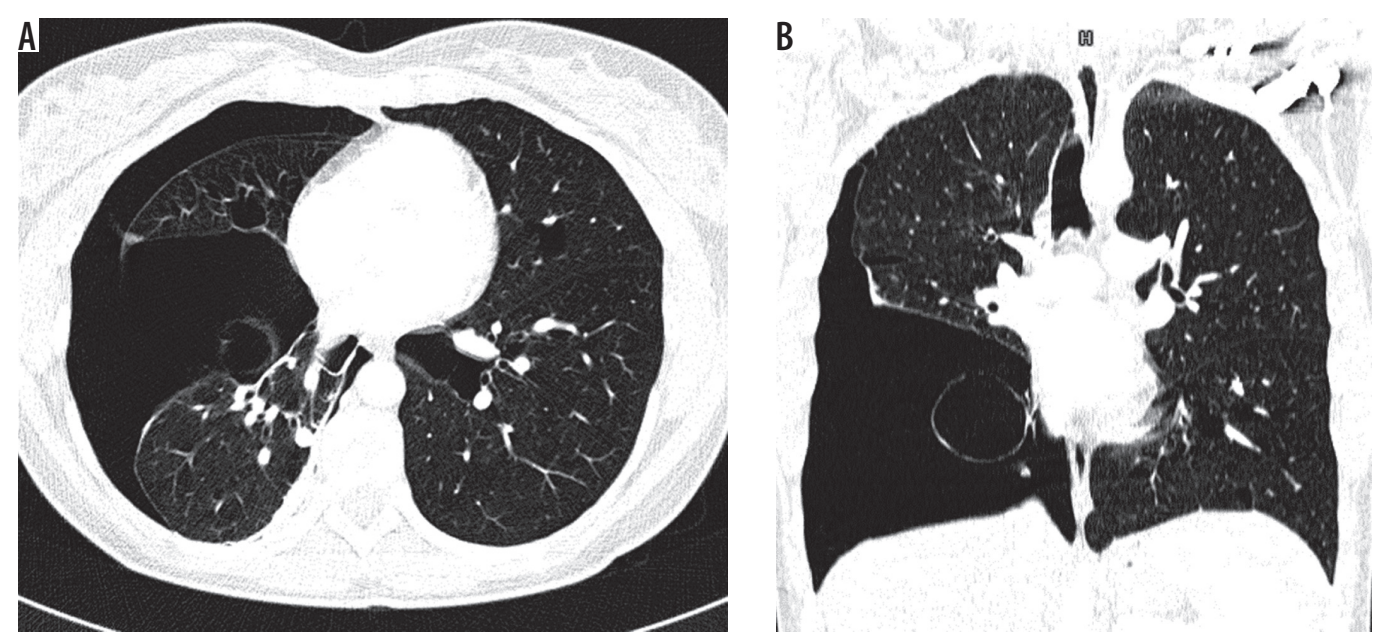

Figure 6. Chest computed tomography, lung window: A) axial plane, B) coronal plane. Recurrent pneumothoraces. There is a right-sided pneumothorax and small cysts in both lungs 
Table 1. Differential diagnosis of Birt-Hogg-Dubé syndrome (BHDS)

\begin{tabular}{|c|c|c|c|c|c|c|}
\hline Variable & BHDS & PLCH & LAM & LIP & Amyloidosis & Emphysema \\
\hline Cysts shape & $\begin{array}{l}\text { Round, oval } \\
\text { or irregular, lenticular, } \\
\text { thin walled }\end{array}$ & Bizarrely shaped & Round & Round & Round & Round, oval \\
\hline Cyst distribution & $\begin{array}{l}\text { Medially in the middle } \\
\text { and lower lung zones }\end{array}$ & $\begin{array}{l}\text { Medially in the upper } \\
\text { and middle lung zones } \\
\text { with sparring } \\
\text { of costophrenic angles }\end{array}$ & Throughout lungs & Lower lung zones & $\begin{array}{l}\text { Throughout } \\
\text { lungs }\end{array}$ & $\begin{array}{c}\text { Upper } \\
\text { and middle } \\
\text { lung zones }\end{array}$ \\
\hline Number of cysts & Moderate & Numerous & Numerous & Moderate & Moderate & Numerous \\
\hline Auxiliary findings & $\begin{array}{c}\text { Kidney } \\
\text { malignancies }\end{array}$ & $\begin{array}{l}\text { Centrilobular nodules } \\
\text { with possible cavitation }\end{array}$ & $\begin{array}{l}\text { AMLs in kidneys } \\
\text { and liver, } \\
\text { lymphangiomas }\end{array}$ & $\begin{array}{c}\text { Centrilobular } \\
\text { nodules ground glass } \\
\text { opacities, thickening } \\
\text { of inter-lobular septa } \\
\text { bronchiectasis }\end{array}$ & $\begin{array}{l}\text { Calcifications } \\
\text { in cyst walls }\end{array}$ & None \\
\hline $\begin{array}{l}\text { Commonly } \\
\text { coexisting diseases }\end{array}$ & None & None & $\begin{array}{l}\text { May be part } \\
\text { of TSC }\end{array}$ & Autoimmune diseases & None & COPD \\
\hline Smoking history & Not important & Positive & Not important & Not important & $\begin{array}{c}\text { Not } \\
\text { important }\end{array}$ & Positive \\
\hline Sex predominance & Equivocal & Equivocal & Woman & Equivocal & Equivocal & Equivocal \\
\hline
\end{tabular}

PLCH - pulmonary Langerhans cell histiocytosis, LAM - lymphangioleiomyomatosis, LIP - lymphoid interstitial pneumonia

lung cysts have positive correlation with pneumothorax occurrence risk. In the patients described in our article, pneumothoraces occurred only in one of the sisters; surprisingly, out of the two she had smaller cysts.

High-resolution computed tomography plays a crucial role in diagnosing BHDS. In differential diagnosis one should include other cystic lung diseases such as: emphysema, lymphangioleiomyomatosis (LAM), pulmonary Langerhans cell histiocytosis (PLCH), lymphoid interstitial pneumonia (LIP), and amyloidosis (Table 1) [9].

Patients with emphysema have a history positive for smoking, and bullae are usually located in upper lung

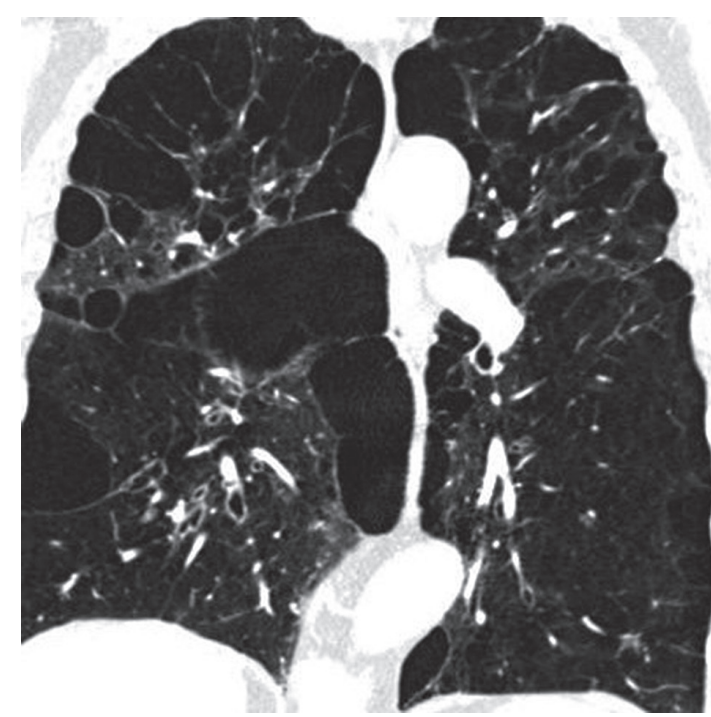

Figure 7. Pulmonary emphysema. Chest computed tomography, lung window, coronal reconstruction, showing severe emphysema in both lungs zones, in contrast to BHDS in which they are generally located below tracheal carina (Figure 7). The greatest difficulty is the differentiation with LAM, especially coexisting with tuberous sclerosis (TSC). In both TSC and BHDS, skin lesions may be present, but in the case of TSC they take the form of: haemangioma, fibromas of the head, periungual fibromas, gingival fibromas, and shagreen patch. In BHDS lung cysts are round, lenticular, or oval shaped, in contrast to round shaped LAM cysts. Most of the lung cysts in BHDS are smaller than $10 \mathrm{~mm}$; however, they can be as big as several centimetres in diameter, as in the presented cases. In patients with LAM the diameter of cysts ranges from 2 to $30 \mathrm{~mm}$. Furthermore, cysts in LAM are evenly distributed throughout both lungs in contrast to

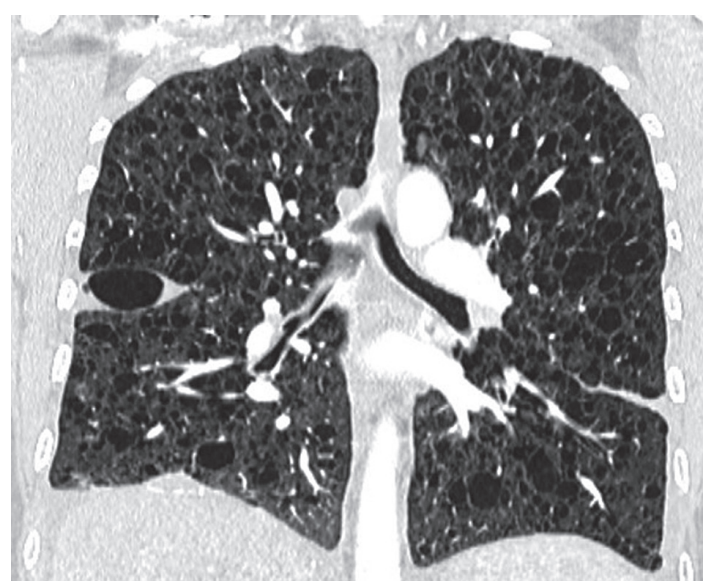

Figure 8. Lymphangioleiomyomatosis, chest computed tomography, lung window, coronal plane showing diffuse lung cysts with regular walls 


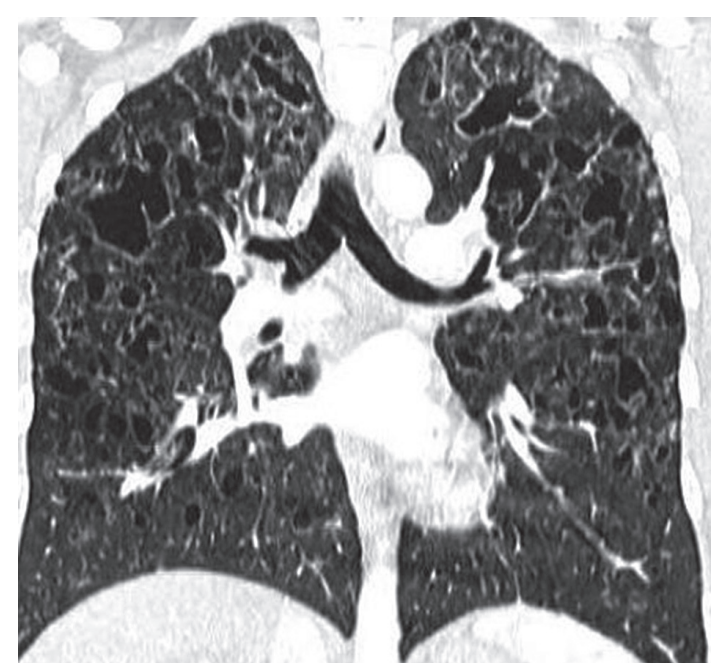

Figure 9. Langerhans cell histiocytosis. Baseline chest computed tomography, lung window, coronal plane demonstrates that the cysts are located predominantly in the upper and middle lung zones with sparing of costophrenic angle

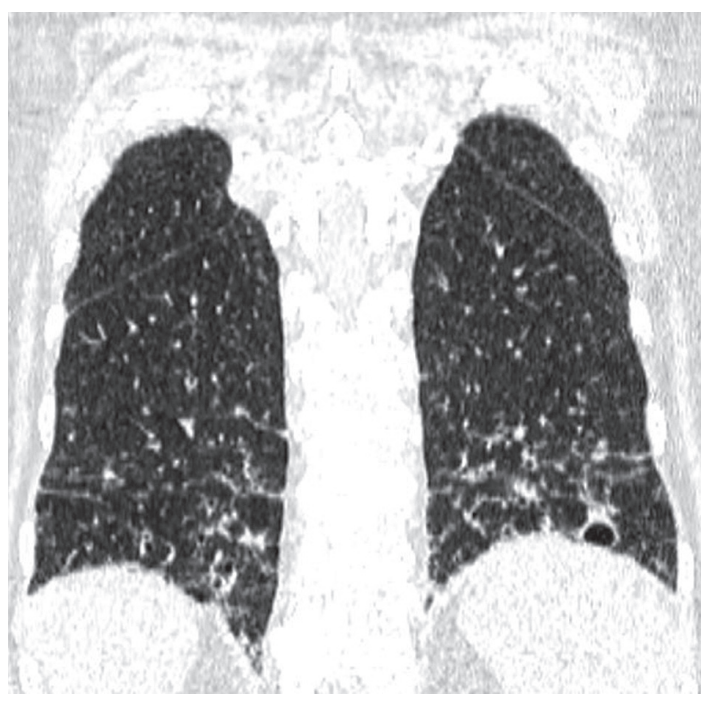

Figure 10. Lymphoid interstitial pneumonia, chest computed tomography, lung window, coronal plane shows thin-walled cysts in a background of diffuse ground-glass opacity in the lower lung zones

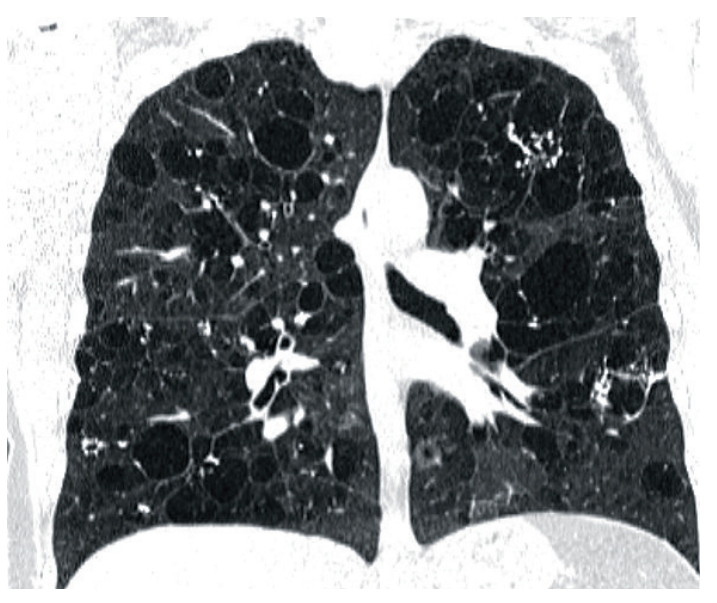

Figure 11. Amyloidosis and lung involvement. Computed tomography scan, lung window, coronal plane. Bilateral pulmonary cysts of widely varying sizes, calcifications in cyst walls
BHDS where they are located in the middle and lower lung zones (Figure 8). Moreover, in BHDS cysts frequently adhere to pleura. BHDS occurs with equal frequency in women and men, LAM is a female disease, and the individual cases of the men described relate to patients with TSC. In patients with BHDS, pneumothorax is less common than in patients with LAM, but the tendency to relapse is similar to that in LAM. In about $80 \%$ of patients with TSC/LAM and about $50 \%$ of patients with sporadic LAM, kidney angiomyolipomas are found, while only about $30 \%$ of patients with BHDS have kidney lesions, both benign and malignant [10]. MRI of the head is useful in differentiating BHDS and TSC. In head MRI of TSC patients one can see cortical/subcortical glioneuronal tubers, subependymal glial nodules (SENs), and subependymal giant cell astrocytomas (SEGAs).

In CT examination of patients with pulmonary form Langerhans cell histiocytosis (occurring almost exclusively in smokers), in addition to bizarrely shaped (sometimes clover leave-like) lung cysts, centrilobular nodules are visible. In PLCH lesions localise in the upper and middle lung fields, saving diaphragmatic angles (Figure 9). The decisive test in these cases is the histological examination of lung samples, in which granulomas consisting of Langerhans cells showing expression of $\mathrm{CD} 1 \mathrm{a}$ and langerin antigens are visualised [11]. In contrast, in patients with BHDS, only features of emphysema are detected in histological examination, as in the second presented case.

Another disease that should be included in differential diagnosis is lymphoid interstitial pneumonia (LIP). Lymphoid interstitial pneumonia belongs to the group of rare interstitial pneumonias and is characterised by the presence of interstitial lung polyclonal lymphocytic infiltrates. In most cases, LIP is associated with autoimmune conditions, especially connective tissue disease (Sjögren's syndrome); however, in rare cases it is an idiopathic disease. The HRCT shows lung cysts of various sizes with clearly defined walls, dominating in the lower lung fields. In addition, there are visible foci of centrilobular nodules, foci of ground glass opacities, thickening of inter-lobular septa, bronchiectasis, and recurrent pneumothoraces. There is a right pneumothorax with small cysts in both lungs (Figure 10).

Cysts are usually less numerous than in LAM and PLCH, but like in BHDS, they are usually located in the lower lung fields [12].

Other disease that can result in an image of lung cysts HRCT is amyloidosis. Amyloidosis is a heterogeneous group of disorders characterised by the deposition of specific fibrillar $\beta$-amyloid proteins in extracellular spaces. However, cystic changes in the lungs in amyloidosis are rare. Variously sized cysts with a well-formed wall often with calcifications are detected (Figure 11) [13].

Patients suspected of having BHDS, as in the presented cases, should undergo genetic testing to identify folliculin gene mutations, which is of pivotal importance 
because a positive test confirms clinical diagnosis and allows for genetic counselling.

\section{Conclusions}

We present the above-mentioned cases to draw attention to the possibility of BHDS occurrence in patients with apparent emphysematous cystic lesions unusually located in the lower and middle pulmonary fields, who also have positive history of pneumothorax, especially recurrent. Diagnosis of BHDS should be followed by pleurodesis when treating the first pneumothorax, and follow-up abdominal ultrasounds because of the risk of kidney malignancies.

\section{Conflict of interest}

The authors report no conflict of interest.

\section{References}

1. Kumasaka T, Hayashi T, Mitani K, et al. Characterization of pulmonary cysts in Birt-Hogg-Dube syndrome: histopathological and morphometric analysis of 229 pulmonary cysts from 50 unrelated patients. Histopathology 2014; 65: 100-110.

2. Goncharova EA, Goncharov DA, James ML, et al. Folliculin controls lung alveolar enlargement and epithelial cell survival through E-cadherin, LKB1, and AMPK. Cell Rep 2014; 7: 412-423.

3. Gupta N, Seyama K, McCormack FX, et al. Pulmonary manifestations of Birt-Hogg-Dube syndrome. Fam Cancer 2013; 12: 387-396.

4. Radzikowska E, Barańska I, Sobczyńska-Tomaszewska A, et al. Familial pneumothoraces: Birt-Hogg-Dubé syndrome. Pol Arch Med Wewn 2016; 126: 897-898.

5. Kunogi M, Kurihara M, Ikegami TS, et al. Clinical and genetic spectrum of Birt-Hogg-Dube syndrome patients in whom pneumothorax and/or multiple lung cysts are the presenting feature. J Med Genet 2010; 47: 281-287.

6. Toro JR, Wei MH, Glenn GM, et al. BHD mutations, clinical and molecular genetic investigations of Birt-Hogg-Dubé syndrome: a new series of 50 families and a review of published reports. J Med Genet 2008; 45: 321-331.
7. Tobino K, Gunji Y, Kurihara M, et al. Characteristics of pulmonary cysts in Birt-Hogg-Dubé syndrome: thin-section CT findings of the chest in 12 patients. Eur J Radiol 2011; 77: 403-409.

8. Zbar B, Alvord WG, Glenn G, et al. Risk of renal and colonic neoplasms and spontaneous pneumothorax in the Birt-Hogg-Dubé syndrome. Cancer Epidemiol Biomarkers Prev 2002; 11: 393-400.

9. Seaman DM, Meyer CA, Gilman MD, et al. Diffuse cystic lung disease at high-resolution CT. AJR Am J Roentgenol 2011; 196: 1305-1311.

10. Toro JR, Pautler SE, Stewart L, et al. Lung cysts, spontaneous pneumothorax, and genetic associations in 89 families with Birt-HoggDube syndrome. Am J Respir Crit Care Med 2007; 175: 1044-1053.

11. Abbott GF, Rosado-de-Christenson ML, Franks TJ, et al. From the archives of the AFIP: pulmonary Langerhans cell histiocytosis. Radiographics 2004; 24: 821-841.

12. Swigris JJ, Berry GJ, Raffin TA, et al. Lymphoid interstitial pneumonia: a narrative review. Chest 2002; 122: 2150-2164.

13. Zamora AC, White DB, Sykes AM, et al. Amyloid-associated. Chest 2016; 149: 1223-1233. 